\title{
A mistura social nos bairros gentrificados: uma brincadeira de criança? ${ }^{12}$
}

\author{
The social mix in gentrified neighborhoods: a child's play?
}

\section{La mezcla social en los barrios aburguesados: un juego de niños?}

\section{Jean-Yves Authier ${ }^{3}$ Sonia Lehman-Frisch ${ }^{4}$}

\section{Resumo}

O artigo trata da questão da mistura social nos bairros gentrificados. Para tanto toma como campo empírico a observação de crianças com idade entre 9 e 11 anos, moradoras da cidade de Paris, França. O trabalho discute a mescla das crianças nos processos de socialização, e analisa os efeitos de classe social e do espaço neste processo. As conclusões indicam que as sociabilidades das crianças, no bairro investigado, são ao mesmo tempo mais numerosas e mais abertas socialmente que aquelas de seus pais e do que as dos adultos dos bairros gentrificados em geral.

Palavras-chave: Gentrificação; Mistura social; Sociabilidades das crianças.

\begin{abstract}
The article deals with the issue of social mixing in gentrified neighborhoods. Therefore takes as empirical field the observation of children aged 9 to 11 years, residents of the city of Paris, France. The paper discusses the mix of children in socialization processes, and analyzes the effects of social class and space in the process. The findings indicate that the sociability of children in the investigated district, are both more numerous and more open socially than those of their parents and the adults of the gentrified neighborhoods in general.
\end{abstract}

Keywords: Gentrification; Social mix; Children sociabilities.

\section{Resumen}

El artículo aborda el tema de la mezcla social en los barrios aburguesados. Por lo tanto toma como cvampo empírico la observación de niños de 9 a 11 años, residentes de la ciudad de París, Francia. El documento analiza la mezcla de los niños en los procesos de socialización, y analiza los efectos de la clase social y el espacio en el proceso. Los resultados indican que la sociabilidad de los niños en el distrito investigado, son a la vez más numerosos y más abiertos socialmente que las de sus padres y los adultos de los barrios aburguesado en general.

Palabras clave: Gentrification; Mezcla social; Sociabilidades de los niños.

1No original: Jean-Yves Authier \& Sonia Lehman-Frisch, “La mixité dans les quartiers gentrifiés: un jeu d'enfants?”, Métropolitiques, 2 octobre 2013. http://www.metropolitiques.eu/La- mixite-dans-les-quartiers.html.

2 Tradução de Cláudia Maia Perdigão e Valéria Milena R. Ferreira e revisão de Márcio de Oliveira.

3 Sociólogo, professor na Universidade Lyon-2 e diretor adjunto do Centro Max Weber (UMR 5283, CNRS). E-mail: Jean-Yves.Authier@univ-Iyon2.fr

4 Geógrafa, Mestre de conferências habilitada a dirigir pesquisas na Universidade de Cergy-Pontoise. E-mail: sonia.lehman-frisch@u-paris10.fr. 
Desde os anos 1980, inúmeras grandes cidades do hemisfério norte são afetadas pela gentrificação: famílias das classes médias altas mudaram para bairros anteriormente ocupados por famílias dos meios populares, produzindo formas mais ou menos duráveis de convivência entre populações de diferentes meios sociais (LEES, SLATER, WYLY, 2008). Até agora, estas relações de coabitação foram quase sempre analisadas por meio das sociabilidades e das práticas locais dos moradores adultos, deixando aparecer uma fraca mistura social entre os habitantes de classes médias altas e os moradores dos meios populares. (CLERVAL, 2008). Entretanto, os bairros gentrificados não se compõem somente de adultos. E quanto às crianças? Como se caracterizam suas sociabilidades? Elas praticam mais a mistura social do que seus pais? Estas questões estão no centro de uma pesquisa que nós realizamos em três bairros gentrificados de Paris, Londres e São Francisco (LEHMANFRISCH, AUTHIER e DUFAUX, 2012).

Em Paris, nossa observação teve por foco crianças com idade entre 9 e 11 anos matriculadas em duas escolas primárias, uma pública e outra particular, localizadas no bairro Batignolles (17- distrito). Antigo bairro popular, procurado por famílias das classes médias altas a partir dos anos 1990, o "batignolles" é hoje um bairro gentrificado, socialmente misto no qual coabitam executivos e pessoas com profissões intelectuais, trabalhadores e empregados (ou antigos trabalhadores e empregados), em um bairro "familiar" onde as crianças estão demograficamente muito representadas e muito visíveis no espaço público. Para compreender a sociabilidade cotidiana das crianças neste bairro, nós conduzimos entrevistas individuais de cerca de 20 minutos, ao longo das quais as crianças (47 no total) eram convidadas a exprimir suas práticas a partir de fotos do bairro. Este material foi completado por outras entrevistas realizadas com seus pais e com seus professores(as) .

\section{Uma "agradável mistura de crianças"}

A análise das relações sociais cotidianas das crianças, na escola, mas também fora dela, no bairro e fora dele, revela primeiro a intensidade das sociabilidades infantis no bairro gentrificado. É o que confirmam os pais, que, interrogados sobre a localização da moradia dos amigos de seus filhos, respondem "o bairro", como se isso fosse evidente. A maior parte das relações das crianças são amigos da escola, que elas veem regularmente no contexto escolar, mas também bastante fora dele. No bairro, muitas crianças convivem igualmente com antigos amigos de escola que elas encontram em atividades extracurriculares, vizinhos(as) ou primos(as). Estas sociabilidades atestam uma fixação local mais importante daquela dos adultos, e particularmente, de seus pais - mesmo se estes últimos reconhecem certo redirecionamento de sua vida social para o bairro, ligada à vinda dos filhos. Essas sociabilidades exprimem, além disso, uma "agradável mistura de crianças" (BALL, VINCENT e KEMP, 2008). Mais frequentemente do que os adultos dos bairros gentrificados em geral, e que seus pais em particular, elas têm, de fato, relações com crianças de meios sociais diferentes do seu.

\section{Sobre relações de mistura social com geometria variável}

Estas sociabilidades numerosas e misturadas ocorrem em diferentes lugares do bairro. Logicamente, a escola constitui um lugar privilegiado. No entanto, as crianças desenvolvem igualmente relações sociais fora da escola. Assim, o Martin Luther King Park, que as crianças entrevistadas citam naturalmente como seu lugar preferido de Batignolles, aparece verdadeiramente como espaço compartilhado do bairro: todas as crianças vão lá (mesmo se elas o fazem com frequência variada) e, mais do que uma área de jogos, para elas é o lugar onde encontram seus companheiros de escola ou de outros lugares, e por vezes até mesmo amigos que conheceram no parque. A moradia (a delas ou aquela dos seus amigos) é outro fundamento importante de suas sociabilidades: elas convidam com frequência seus amigos (ou são convidados para ir à casa deles) para suas festas de aniversário, para brincar algumas horas ou ainda para "festas de pijama". As atividades esportivas, lúdicas ou culturais das quais elas participam na escola (fora do tempo escolar - por exemplo, no âmbito das "Oficinas Azuis" 
organizados pela prefeitura), no bairro, e mesmo fora dele, são também lugares onde desenvolvem relações que podem ser ou não prolongadas em outros contextos. Observamos que segundo o gênero, as crianças utilizam estes lugares diferentemente: os meninos tendem mais a encontrar seus amigos de escola no parque, enquanto as meninas, mesmo se encontram por vezes suas amigas lá, convidam-nas mais para ir às suas casas.

As sociabilidades que ocorrem nestes diferentes lugares não são exatamente as mesmas e tudo acontece como se as crianças realizassem uma mistura de geometria variável. Assim, a mistura social desenvolve-se de maneira mais marcada na escola do que no bairro. A maior abertura à mistura no âmbito da escola está ligada à composição social das classes estudadas (e, mais amplamente, de suas escolas), compreendendo, tanto numa quanto noutra, crianças vindas de camadas populares e de classes médias altas. No entanto, ela é mais acentuada na escola pública do que na escola particular. Na primeira, que se caracteriza por um leque mais amplo das categorias profissionais dos pais, quase todas as crianças interrogadas têm afinidades com companheiros de outro meio social. Na segunda, onde o espectro da origem social das crianças é mais restrito, as sociabilidades, em seu conjunto, são ligeiramente menos misturadas. No bairro (fora da escola), com exceção do parque que constitui um lugar de convívio das crianças de diferentes meios sociais, as sociabilidades tendem a ser menos mistas do que na escola: na moradia, nas atividades extracurriculares e nos outros lugares do bairro (e mesmo fora dele), as relações sociais das crianças ligam-se preferencialmente ao seu próprio meio social.

\section{Efeitos de classe... e efeitos do espaço}

A mistura das sociabilidades infantis em função dos lugares, é estruturada pelos efeitos de classe. As crianças das classes médias altas revelam assim relações sociais mais mistas do que aquelas das camadas populares ou, mais precisamente, elas tendem a acumular relações de diferentes meios sociais em diversos lugares. Na escola, elas revelam sociabilidades mais mistas do que as crianças de origem popular. Fora da escola, elas redirecionam suas relações para as crianças do mesmo meio social e elas encontram seus amigos durante atividades extracurriculares, por vezes no parque, mas principalmente em casa, por meio de convites mútuos; se elas também convidam ocasionalmente as crianças de origem popular para virem em sua casa, elas vão muito raramente às casas delas, o que revela uma importante dissimetria social no uso da moradia.

Quanto às crianças das camadas populares, elas têm sociabilidades relativamente menos mistas na escola que seus companheiros de camadas médias altas; fora da escola elas convidam menos frequentemente seus amigos a virem às suas casas (em razão das condições de moradia percebidas como menos favoráveis, por vezes mesmo desfavoráveis), com maior razão ainda quando os amigos são oriundos das camadas médias altas. Estas crianças (e mais ainda os meninos) desenvolvem suas sociabilidades (principalmente populares) preferencialmente no parque do bairro.

Globalmente, a tendência a uma menor abertura das sociabilidades no bairro do que na escola, o que vale tanto para as crianças de origem popular quanto para aquelas das classes médias altas, corresponde a duas lógicas diferentes. As primeiras parecem obedecer a uma lógica de isolamento social: suas relações são mais impostas do que escolhidas, uma situação frequentemente reforçada por fortes sociabilidades familiares favorecidas pela proximidade geográfica da família. Pelo contrário, para as crianças das classes médias altas, é como se seus pais realizassem um reequilíbrio social em relação às sociabilidades mais mistas mantidas na escola, controlando as companhias de seus filhos através dos convites à moradia, da seleção das atividades extracurriculares, etc.

Esta influência do meio social sobre a abertura das sociabilidades infantis é modulada pela distância espacial (do domicílio em relação ao bairro). Isso é particularmente claro no caso das crianças do meio popular, como mostra o caso das crianças de origem popular da escola pública, que nem sempre moram no bairro Batignolles: enquanto as que moram no bairro gentrificado têm alguns amigos vindos das classes médias altas, esse caso 
é menos frequente para aquelas que moram no bairro popular vizinho Épinettes, cujas sociabilidades são muito mais voltadas para o seu próprio meio social. Em outras palavras, a proximidade espacial favorece aqui a proximidade social e abre as crianças a certa mistura social entre "vizinhos".

\section{Sociabilidades sob controle}

As crianças não desenvolvem suas sociabilidades de forma independente; estas são, evidentemente, em parte estruturadas pelas estratégias educativas dos pais. Isso é particularmente verdadeiro para as classes médias altas. Esses pais insistem de maneira bastante consensual sobre a necessidade, para seus filhos, de um aprendizado da mistura. No entanto, eles tendem a enquadrar suas sociabilidades muito mais estritamente do que o fazem os pais de origem popular: acompanhando quase sistematicamente seus filhos ao parque, recebendo seus amigos da escola (e particularmente aqueles de origem popular) em sua moradia, ou encorajando a prática de atividades extracurriculares distintivas (e portanto o encontro com outras crianças do mesmo meio social), tudo ocorre como se eles encorajassem a abertura das relações sociais de seus filhos, mantendo-os porém sob controle.

Ao mesmo tempo, esses pais de classes médias altas, em sua estratégia educacional, nem sempre atribuem a mesma importância à mistura social e ao bairro; em função disso, eles encorajam mais ou menos a abertura das sociabilidades de seus filhos. Em consequência, eles são mais ou menos inclinados a expor seus filhos a ela, segundo os lugares onde ela se desenvolve. Isso se exprime, com certeza, na escolha da escola, pública ou privada, mas não apenas aí. Tal mãe (professora de escola), por exemplo, considerando o bairro como "uma escola da vida", estima importante que seu filho seja confrontado à mistura social ao mesmo tempo na escola pública, na moradia e no bairro em geral, o que se traduz por uma real mistura social das sociabilidades de seu filho. Pelo contrário, para outra mãe (arquiteta), "a diversidade social tem seus limites", e se ela tolera a mistura das relações sociais de sua filha no âmbito da escola primária pública, ela se esforça - com sucesso - em reequilibrar suas sociabilidades organizando a maior parte da sua vida social em seu meio social, fora do bairro, com crianças que "se parecem" com sua filha, que são "enquadradas em casa por seus pais".

\section{Conclusão}

As sociabilidades das crianças, no bairro Batignolles, são ao mesmo tempo mais numerosas e mais abertas socialmente que aquelas de seus pais - e do que aquelas dos adultos dos bairros gentrificados em geral. Ao mesmo tempo, a abertura das sociabilidades diminui de maneira claramente diferenciada segundo os lugares do bairro (escola, moradia, parque etc.), e segundo os meios sociais, enquanto os pais, e mais particularmente aqueles das classes médias altas, desempenham um papel fundamental na organização da vida social de seus filhos. Tais sociabilidades misturadas têm consequências sobre as práticas: convivendo com crianças de outros meios sociais, as crianças desenvolvem práticas que se assemelham. Assim, com relação ao que foi observado em outros contextos urbanos (LAREAU, 2003), as crianças de classes médias altas do bairro Batignolles vão mais frequentemente ao parque, e as crianças de meios populares participam mais de atividades organizadas. Encontram-se esses grandes resultados nos outros dois bairros gentrificados de nossa pesquisa, em São Francisco e em Londres, contudo, com algumas diferenças: em Noe Valley (São Francisco), por exemplo, as sociabilidades das crianças são consideravelmente mais dispersas do que em Batignolles, em razão de uma mais fraca densidade do habitat e de um sistema de matrícula escolar que não depende do princípio de setorização geográfica. Além disso, como as crianças de origem popular e aquelas das classes médias moram a uma maior distância umas das outras, elas tendem muito menos a se encontrar fora da escola. Enfim, em Noe Valley, os pais das classes médias altas percebem a questão da mistura (para encorajá-la ou freá-la nas sociabilidades de seus filhos) mais dos pontos de vista étnico, da orientação sexual (das famílias) e mesmo de pessoas com necessidades especiais, do que ponto de vista social. 


\section{Referências Bibliográficas}

BALL, S.; VINCENT, C.; KEMP, S. "Un agréable mélange d'enfants...": prise en charge de la petite enfance, mixité sociale et classes moyennes, Education et Sociétés, n 14, p. 13-31. 2004

CLERVAL, A. La Gentrification à Paris intra-muros : dynamiques sociales, rapports sociaux et politiques publiques, thèse de doctorat en géographie, université de Paris-1. 2008.

LAREAU, A. Unequal Childhoods: Class, Race and Family Life, Berkeley: University of California Press. 2003

LEES, L.; SLATER, T.; WYLY, E. (dir.). Gentrification, New York/Londres: Routledge. 2008

LEHMAN-FRISCH, S. (dir.); AUTHIER, J. Y.; DUFAUX, F. Les enfants et la mixité sociale dans les quartiers gentrifiés à Paris, Londres et San Francisco, Dossier d'études, n 153, Caisse nationale des allocations familiales. 2012.

Recebido em outubro de 2014 | Aprovado em maio de 2015 